González Martínez, Felip.

Doctor en Bellas Artes, Universitat Politècnica de València. Investigador del Proyecto $1+D$ ref. HAR2014-58869-P del Ministerio de Economía y Competitividad.

\title{
Protoacciones artísticas en la Valencia del primer franquismo (1939-1959): prácticas locales bajo el desconocimiento global.
}

\section{Proto-action arts in the Valencia of the first part of Franco's dictatorship (1939-1959): local practices under the global ignorance.}

\author{
TIPO DE TRABAJO:
}

Comunicación.

PALABRAS CLAVES:

Performance, happening, arte de acción, primer franquismo, arte valenciano.

KEY WORDS:

Performance, happening, action art, the first part of Franco's dictatorship, Valencia art.

RESUMEN.

Esta intervención se centra, en sacar a la luz y dotar un valor plástico aquellas acciones artísticas que, materializadas por artistas y agrupaciones de arte, orbitaron en la Valencia del primer franquismo (1939-1959). Acciones que, independientemente de su naturaleza y singularidad, deberían formar parte de la historia universal de la performance, desde el filtro de la intrahistoria artística de la ciudad de Valencia.

Se pretende rescatar y analizar todas las posibles experiencias prácticas del mundo de la acción artística que, debido a su indefinición formal y desconocimiento conceptual, no fueron percibidas, artísticamente hablando, a los ojos de los artistas, la crítica de arte y la historia del arte. En este contexto, se ha de recuperar y enfatizar las propias acciones artísticas per se del conjunto de propuestas, que participaron en los inicios del arte moderno valenciano. De forma más descriptiva, se tratarían de gestos, actitudes, sucesos y situaciones desarrollados en contextos activistas de rebeldía, en las aulas o cercanías de la Escuela Superior de Bellas Artes de San Carlos, en exposiciones o eventos públicos, en tertulias artísticas y literarias, etc. $Y$, en general, se trataron de acciones más azarosas y aventureras que, debido al estancamiento cultural autárquico del franquismo, poco tuvieron que ver con la tradición performática de los artistas futuristas, dadaístas o constructivistas.

Finalmente, es necesario entender, enfatizar y, a su vez, reivindicar la idiosincrasia y el valor plástico de cada acción artística, enmarcados dentro de la marginalidad local de la ciudad de Valencia, del aislamiento cultural nacional de los años 40 y 50, y de la coincidencia de premisas en las performances y los happenings desarrollados en los Estados Unidos de América, Europa y Japón.

ABSTRACT.

This article focuses on bringing to light and providing those actions with artistic value that were realized by artists and groups located in Valencia during the first stage of the Franco regime (1939-1959). Actions independently of their nature and singularity should be part of the universal history of performance and internal artistic history of the city of Valencia. 
The aim is to recover and analyze all possible practical experiences in the world of action art that, due to their formal nondefinition and conceptual ignorance, were not perceived of as artistic by artists, art criticism and history of art. In this context, it is necessary to recover and stress action art per se in relation to the set of proposals central to the beginnings of Valencian modern art. In a more descriptive way, these artistic practices were gestures, attitudes, events and situations developed in rebel activist contexts, in the classrooms of the School of Fine Arts of San Carlos and its vicinity, in art exhibitions or public events, in artistic social circles, etc. In general, these actions were more of an eventual and adventurous nature due to the autarchic cultural stagnation of the Franco regime and had little to do with the tradition of performances of futurist, dadaist or constructivist artists.

Finally, it is necessary to understand, emphasise, as well as claim the idiosyncrasy and artistic value of each instance of action art in the context of the local marginality of the city of Valencia, the national cultural isolation between the 1940s and 1950s, and the coincidence of premises for actions and events developed in the United States of America, Europe and Japan.

\section{CONTENIDO.}

\section{Protoacciones artísticas en la Valencia del primer franquismo (1939-1959): prácticas locales bajo el desconocimiento global.}

\section{Introducción.}

Mi intervención en este congreso se centra en sacar a la luz y reivindicar aquellas situaciones y gestos artísticos acaecidos en el contexto cultural y sociopolítico de la Valencia del primer franquismo (1939-1959). Se entiende por situación o gesto artístico, como aquellas prácticas artísticas no convencionales que, por un lado, se desprende de los cánones tradicionales del lenguaje y del formato material del dibujo, el grabado, la pintura o la escultura, y, por otro lado, potencia el estado efímero de las acciones (más cercanas a la "autopresentación" o gesto corporal de los artistas que a sus formas de "representación" artística) que se suceden y desarrollan en un espacio transitorio y en un tiempo efímero. En otras palabras, se hace referencia a aquellas experiencias protoperformativas y a la práctica azarosa de los protohappenings (una denominación porque que antecede a la idea posterior de happening creada por el artista Fluxus Allan Kaprow en 1959), al ser materializadas por los mismos artistas y agrupaciones de arte que vislumbraron la vuelta, pero reinterpretada con nuevos ojos, del arte de preguerra y la gestación de los primeros indicios del arte moderno, conectando así con el arte europeo occidental. Prácticas artísticas que, independientemente de su naturaleza, registro y singularidad, deberían formar parte de la historia universal del arte en acción español, desde el filtro de la intrahistoria artística de la ciudad de Valencia.

\section{Desarrollo.}

La cronología propuesta en esta comunicación, se adentra, de forma arqueológica, en los años del primer franquismo (1939 y 1959). Una controvertida época, donde el advenimiento de la dictadura de Franco, "a sangre y fuego", se ganó el respeto, el miedo y la obediencia adepta al Caudillo. En materia artística, la consolidación cultural del establishment franquista, especialmente en un primer periodo (entre 1939 y 1945), se tradujo en una permisiva convivencia entre las diferentes ortodoxias oficiales, que fueron desde un lenguaje más militante con el nacionalcatolicismo y las posturas falangistas ${ }^{1}$, pasando por el continuismo del frío academicismo y el insípido realismo decimonónico, la repetitiva pintura de género, o bien las diferentes visiones regionales; hasta llegar a la tolerancia del aggiornamiento orsiano, que representó un faro hacia un arte más expresivo, vivo e innovador, materializado en las conocidas Exposiciones antológicas y las muestras del Salón de los once.

En medio del anodino y asfixiante ambiente oficialista, latía entre los hijos de la generación de la guerra (desde mediados de los años 40), un contundente hartazgo desafiante hacia las tradicionales enseñanzas artísticas, la cultura de la censura, el fanatismo religioso de estampitas, y el mundo de los concursos y exposiciones nacionales. Dicha desolación cultural fue paliada por la gestación de un incipiente caldo de cultivo, que canalizó la queja y el descontento general, a través de la proliferación de agrupaciones de arte (Los Siete, Dau al Set, LADAC, Pórtico, Los indalianos, etc.), la adhesión y fomento de lenguajes más novedosos en exposiciones puntuales y periódicas (Círculos de Arte Experimental y Salones de Octubre en Barcelona), el intercambio de ideas artísticas y filosóficas en cursos de arte (Escuela de Altamira), la organización de actividades culturales transversales -recitales de poesía, conferencias o audiciones de música-, la interconexión entre profesionales de las diferentes disciplinas humanísticas, la difusión del pensamiento estético en revistas y monografías de artistas, etc. En consecuencia, el conjunto de estas propuestas plásticas ayudó a traspasar la frontera del miedo, a recuperar el arte moderno de preguerra, a conectar con el arte más innovador europeo y, fundamentalmente, a conformar el futuro del arte moderno peninsular en una suerte de giro lingüístico no figurativo en la década de los años 50 . Estos nuevos horizontes en

\footnotetext{
${ }^{1}$ La convivencia de los diferentes programes culturales oficiales, se podrán analizar mejor en la obra de Llorente Hernández, Á.1995. Arte e ideología en el franquismo. Madrid: Visor.
} 
forma de abstracción lírica, informalista y geométrica, a partir del año 1957, supuso la normalización oficial del arte moderno y el predominio, un tanto dogmático, de los lenguajes normativistas en exposiciones, publicaciones y discursos artísticos.

En el contexto valenciano, en el seno de las emergentes iniciativas individuales de un Manolo Gil o de un Eusebio Sempere y de las propuestas colectivas de las agrupaciones $Z$, Los Siete y, más tarde, Parpalló, Rotgle Obert y la plataforma del Movimiento del Arte del Mediterráneo, se gestaron una serie de acciones artísticas significativas, desde los imprevisibles marcos de las aulas, las cafeterías, las exposiciones, los grupos, etc. Acciones, gestos, situaciones, acontecimientos o sucesos artísticos que, desde el desconocimiento conceptual, la primacía de los formatos plásticos tradicionales y su escaso testimonio documental, se ha podido constatar la conversión de la queja en forma de protesta y rebeldía, el intercambio de ideas entre contertulianos de café y vino, las propias dinámicas operativas del trabajo en grupo, el componente azaroso y espontáneo, el efecto sorpresa, y el principio teatral de la improvisación, detonante activo de las acciones artísticas.

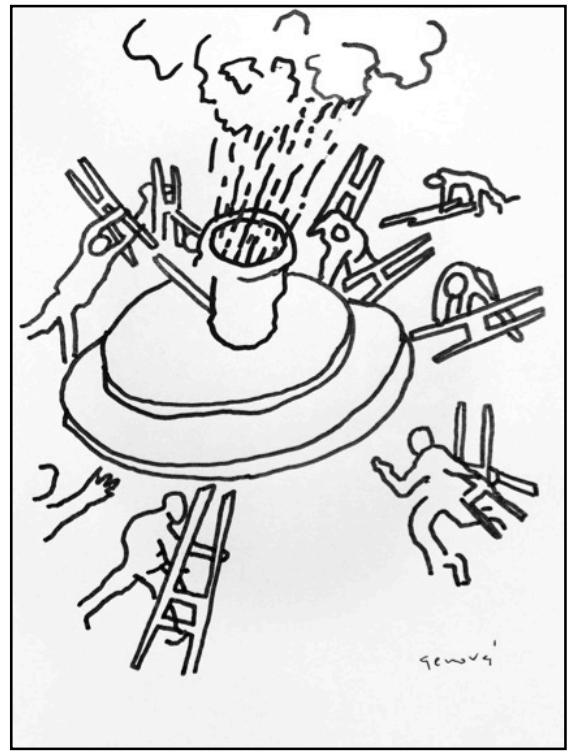

\section{Alumnos quemando los caballetes en uno de los pozos de la Escuela Superior de Bellas Artes de San Carlos de Valencia, 1948. Dibujo inédito de Juan Genovés, diciembre del $2016^{2}$.}

Desde mediados de los años 40, los alumnos de la Escuela Superior de Bellas Artes de San Carlos manifestaron su hartazgo contra el arraigado conservadorismo académico y el abusivo sorollismo, a través de enfrentamientos estéticos entre alumnos y profesores, la adhesión rebelde de ennegrecer y embetunar, voluntariamente, sus composiciones pictóricas, y la participación en una memorable acción de protesta, a propósito de la visita del Director General de Bellas Artes, el Marqués de Lozoya, hacia el año 1948 en la escuela. El pintor Juan Genovés, entonces alumno e iniciador del grupo de Los Siete, explica en varias entrevistas, que normalmente las instalaciones de la escuela se encontraban en un estado deplorable y la falta de recursos económicos, obligaba que se careciera de modelos a pintar, siendo los propios alumnos los que hacían de modelo entre sí. No obstante, ante la visita del Marqués de Lozoya, de forma repentina, se limpiaron las infraestructuras de la escuela y se colocaron nuevos caballetes en las aulas. Ante esta sorprendente situación, muchos alumnos orquestaron un verdadero happening de protesta, que consistió en ensuciar los patios, de lanzar los caballetes viejos dentro de un pozo (de uno de los dos claustros), donde fueron luego quemados. A continuación, se pasará a citar textualmente lo sucedido por el artista Juan Genovés con estas palabras ${ }^{3}$ :

"Llegó un día que se llenó el aula de caballetes nuevos. Los que teníamos eran una porquería, inestables y sin peso, casi inútiles, se pintaron las aulas, se limpiaron los suelos, las puestas y tiempos después nos enteramos de la visita, con el dinero que se ahorraron de los modelos. Asearon la Escuela que era un asco para enseñar al Sr. Marqués de Lozoya."

Retomando las controvertidas disputas entre alumnos y profesores, se ha de señalar las discusiones del pintor Manolo Gil con los profesores de la escuela, sobre todo con el Catedrático de Colorido, el profesor Salvador Tuset, sobre la caducidad del academicismo y

\footnotetext{
${ }^{2}$ Dibujo incluido en la entrevista inédita realizada al pintor Juan Genovés, titulada Entrevista a Juan Genovés sobre el período de formación y la época de Los Siete, enviada el 22 de octubre del 2016 y contestada, vía email, el 4 de diciembre del 2016. Dibujo inédito cedido a un servidor para fines orientados a la investigación. ${ }^{3}$ ídem.
} 
la perpetuación estéril del sorollismo. Muchos otros alumnos coetáneos a Gil, consideraban al catedrático como una buena persona, pero paternalista y corto de miras. En palabras de Vicente Gómez García y luego de Juan Genovés, a su cátedra se la conocía como el "tontódromo" ${ }^{4}$, donde en ocasiones, ante sus propuestas coloristas, algunos de sus alumnos se decantaron, a modo de acción contracolorista, utilizar solo la paleta del color negro, que era más propia del tenebrismo o de las pinturas negras de Goya, a la que Tuset reaccionaba que estaban "mal de la vista", para cualquiera que pintara solo con blanco y negro en Valencia:

"Nosotros vivimos en una región de mucha luz y mucho color, y por lo mismo no podemos prescindir de ambas cosas, so pena de incurrir en falta grave como pintor. Pintar en blanco y negro en esta región es el absurdo más grande del mundo. Al que pinta negro ¿Ud. lo ve así? Vd. Está muy mal de la vista" ${ }^{5}$.

Para concluir el párrafo, existe otra anécdota de otro profesor, en este caso del entonces director de la escuela, el profesor Sanchis Yago, a quién se le hizo una acción de protesta anónima, que consistió en añadir el nombre del citado director detrás de la calle que rezaba con el nombre del Cabrito. Una acción estratégica, ya que se encontraba en las inmediaciones de la escuela y, a su vez, desafiante, ya que canalizaba la disconformidad del alumnado, al modo de arte callejero, como un clandestino gesto de protesta.

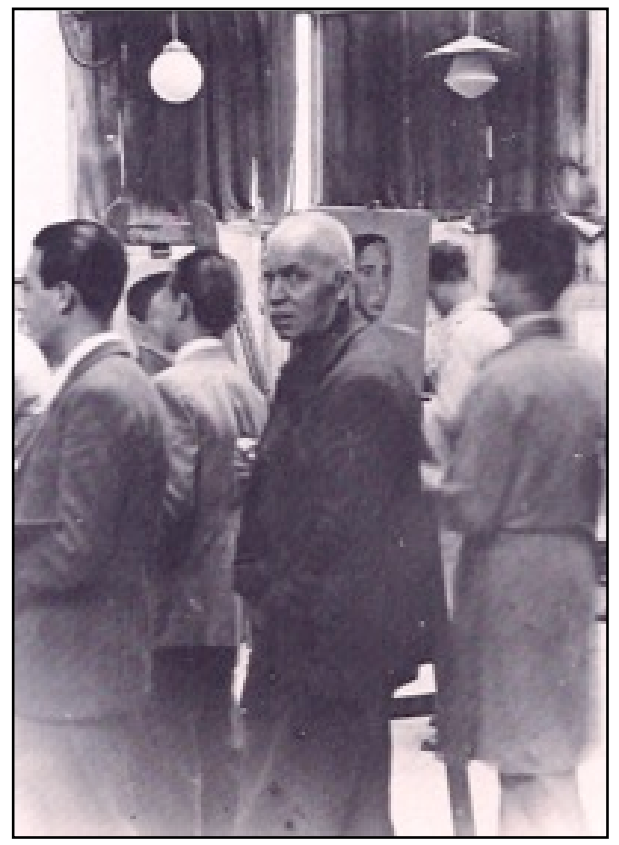

\footnotetext{
Tuset en la clase de colorido de la Escuela Superior de Bellas Artes de San Carlos (Valencia, 1949) ${ }^{6}$. Esta clase era denominada "tontódromo", donde algunos de sus alumnos hicieron una acción contracolorista de pintar solo en negro.
}

En cuanto al ámbito de las tertulias artísticas, en esta época, muchas cafeterías y tabernas fueron irrumpidas por grupos de contertulianos en la ciudad de Valencia, como fueron las tertulias de Los vesperales realizadas en una casa particular en el barrio de Patraix, las sesiones del grupo $Z$ en la tasca Casa Pedro, las charlas artísticas de la agrupación Los Siete en el café la Lonja y la cafetería Lara, y el popular grupo de contertulianos de Manuel Real Alarcón. De todas las tertulias nombradas, se rescatará las tertulias coordinadas por Real Alarcón, entre los años 1948 i 1957, materializadas en el café Fénix y les cafeterías Lara y Monterrey. Las aventuras de estos contertulianos fueren narradas en el libro Historia de los Libres de Oro de las tertulias de pintores y escultores valencianos, a lo largo de tres volúmenes que el autor iba llevando durante los veinte años de existencia de las tertulias, conjuntamente con los diferentes materiales para trabajar.

\footnotetext{
${ }^{4}$ La primera vez que escuché la expresión de "tontódromo" fue en boca de Vicente Gómez, a propósito de una inédita entrevista con el pintor Gómez en su domicilio de Valencia, el día 16 de mayo del 2009. Más tarde, en otra entrevista realizada a Genovés, en su apartamento de El Perellonet (septiembre de 2016), Genovés aclaraba que el "tontódromo" hace referencia a la cátedra del profesor Salvador Tuset, porque exaltaba el empleo de los colores fuertes, desde una empalagosa vehemencia y paternalismo hacia los alumnos.

${ }^{5}$ Citado por KURTZ MUÑOZ, J.A. 1978. El pintor Salvador Tuset. València: Intitució Alfons el Magnànim; Caja de Ahorros y Monte de

Piedad de Valencia, p. 151.

${ }^{6}$ Ídem. Imagen LXVII.
} 
Cada libro es el fruto de una literatura testimonial que recogía ideas, disputas y experiencias de las diferentes etapas de estos encuentros. Al mismo tiempo, estos libros ayudaron a no dejar perder los dibujos y pinturas de los artistas, que al principio se solían concebir en espontáneas servilletas de cafetería. La manera de concebir los retratos de los asistentes, se les podría considerar como un tipo de acción artística, dado a su agilidad ejecutiva y alto grado de espontaneidad resolutiva. Son obras que, al modo de las actuales pruebas de pintura rápida, desafiaron con genialidad y destreza cualquier contrariedad temporal, espacial, o bien de planificación previa. En este aspecto, se destaca la gran hazaña ejecutada por el pintor Michavila, también miembro activo de Los Siete, quién resolvió, de forma favorable, los doce retratos de los asistentes de entonces. Una hazaña que se le identificaría como un auténtico gesto performativo, porque reunía los ingredientes de la transitoriedad del momento, la agilidad gestual, el esfuerzo de un breve programa resolutivo y un alto grado de espontaneidad. Manuel Real Alarcón relató la hazaña de Michavila del siguiente modo ${ }^{7}$ :

"La hazaña larga, sin par, magna, jamás batallada en estos Libros de Oro, la realiza Michavila, en la tertulia del 13 abril 56, dibujando los retratos de todos los asistentes (...)"

En la misma línea anterior, el mismo artista de antes, instaba a sus compañeros a realizar obras abstractas en tres minutos. De nuevo, se trata de otro gesto performativo que apostaba por la plasmación y elaboración de un lenguaje plástico menos tradicional, porque pretendía medir las destrezas técnicas de cada componente y visualizar los ágiles procesos creativos, en base de un gesto más azaroso, desenfadado, y, en definitiva, expresivo.

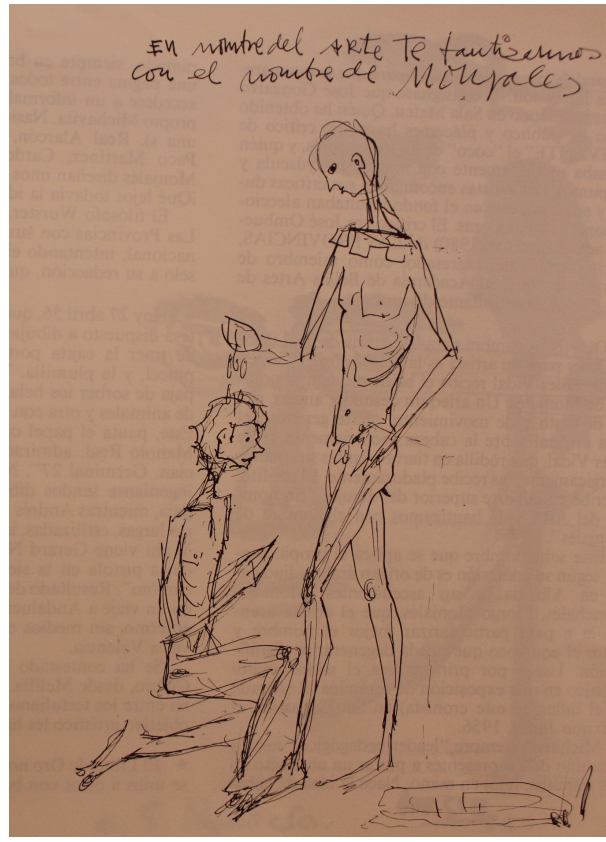

Bautismo de Monjalés, ilustración para el I Libro de Oro, ubicada en la página $203^{8}$.

Y concluyendo el mundo de las tertulias de Alarcón, se debe de destacar, como hecho extraordinario, la especie de happening bautismal que hicieron los compañeros de tertulias al artista José Soler Vidal, en lo sucesivo conocido como Monjalés, el día 20 de abril de 1950 en la cafetería Monterrey. Este bautismo simbólico fue ilustrado por el propio artista, en la página 203 del I Libro de Oro. Se puede apreciar un arlequín bautizando al artista y arriba del todo se podía leer "En el nombre del Arte te bautizamos con el nombre de Monjalés".

Cambiando de tercio, dentro del ámbito de los grupos artísticos, resulta muy acertado nombrar a la agrupación de Los Siete que, orbitando entre los años 1948 y 1954 en la ciudad del Turia, dio los primeros pasos para despertar el somnoliento ambiente oficial y para inyectar nuevas propuestas plásticas y culturales, a través de exposiciones, tertulias de arte, conferencias, audiciones de música, etc. La excepcionalidad de esta agrupación, residiría en la manera de confeccionar los catálogos de mano, porque, a pesar de su reproducción mecánica en una imprenta, siempre se dejó un espacio en el anverso para que cada componente lo personalizara

\footnotetext{
${ }^{7}$ Texto extraído de REAL ALARCÓN, M. 1985. Historia de los libros de Oro de las Tertulias de pintores y escultores valencianos. Valencia: Ayuntamiento de Valencia, p.116.

${ }^{8}$ Representa la acción simbólica de cambiar el nombre de José Soler por su nombre artístico de Monjalés. Ilustración extraída del libro REAL ALARCÓN, Cit., p. 37.
} 
manualmente. Para este propósito, se organizaban sesiones de trabajo conjuntas en casa de un artista, con el fin de pintar manualmente - ya sea en acuarela o tinta china-, sus ilustraciones. La temática gráfica de cada invitación venía sugerida por un artista, ya que de forma rotativa, el artista de turno, decía en voz alta un concepto. Por tanto, los motivos representados, en las 300 o 500 invitaciones de cada inauguración, eran producto de una azarosa acción colectiva que, de un modo ágil y efímero, los artistas hablarían sobre el propio proceso gestual y gesto artístico de cada ilustración ${ }^{9}$.

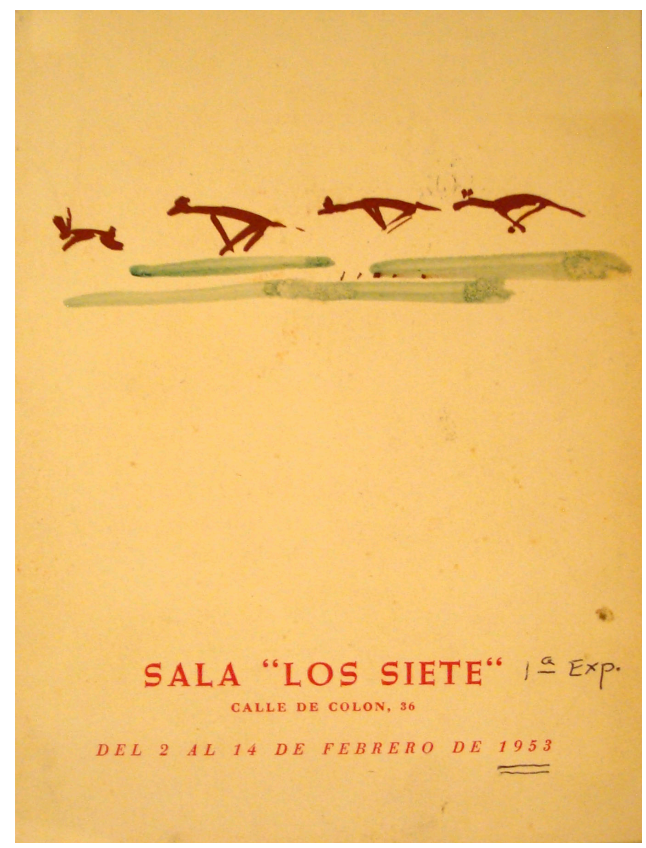

Catálogo de mano para la exposición del grupo de Los Siete en Sala Colón, Valencia, del 2 al 14 de febrero de $1953^{10}$.

Otro aspecto a tener en cuenta sobre el citado grupo de Los Siete, hace referencia a la primera época expositiva en la tienda de muebles de la calle Colón número 38 de Valencia. Local que el tío de Juan Genovés, Vicente Genovés, prestó a la joven formación como sala de arte, durante la franja horaria de las 19 a las 21 horas. Ante las limitaciones espaciales, los artistas tuvieron que condicionar la sala, es decir, de pintar las paredes, colocar colgadores, etc. Para más inri, durante el tiempo que duraban las exposiciones, los artistas se vieron obligados, al modo de happening colectivo, normalmente con escaso público de amigos o ninguno, de guardar los muebles en la trastienda y, a su vez, acondicionar el espacio expositivo con un papel continuo en las paredes. Y, una vez finalizada la jornada, tenían que volver a colocar los muebles en su sitio y desmontar los cuadros, el papel continuo, etc. Un trabajo agotador que solía repetirse, entre los años 1950 y 1953, los días que transcurrían las exhibiciones.

\section{Conclusiones.}

Hasta aquí, se ha pretendido visualizar situaciones, eventos y acciones que, en función de su naturaleza artística, podrían constituirse como antecedentes rudimentarios y emergentes de las futuras acciones artísticas que, en forma de performance o happening, sucedieron en Japón con el grupo Gutai (1955), en los Estados Unidos con los estudiantes de Black Mountain College en su sede del Lago Eden (1941-1956) o la famosa obra 18 happenings en 6 partes del artista Allan Kaprow (Reuben Gallery, Nueva York, 1959), las acciones de la plataforma Fluxus (1962), el "arte auto-destructivo" iniciado por Gustav Metzger en el Destruction in Art Symposium (Londres, 1966), o bien las provocaciones performativas de los alemanes Wolf Vostell o Josep Beuys. Prácticas rudimentarias que, sin tener consciencia semántica, experiencia procesual de las acciones y, mucho menos, consignas del mundo escénico y poético, han conseguido expresar realidades, sensaciones e ideas con mayor dinamismo, improvisación y experimentación gestual.

\footnotetext{
${ }^{9}$ En la tesis doctoral de GONZÁLEZ MARTíNEZ, F. 2015. La incidència de l'agrupació artística d'Els Set (1948-1954) en les primeres petjades de l'art modern valencià del primer franquisme. Valencia: Facultad de Bellas Artes, UPV, se analiza la naturaleza, los objetivos, las actividades culturales, las tertulias y la trascendencia artística de la formación valenciana, en el controvertido contexto cultural del primer franquismo, tanto a nivel local y peninsular.

${ }^{0}$ Este catálogo forma parte del archivo de la pintora Ángeles Ballester. Información extraída de una entrevista inédita con Ángeles Ballester, 22/12/09, Valencia.
} 
Finalmente, se trataron de acciones individuales o colectivas que, en base del azar, la diversión y la aventura, se interesaron en conquistar el espacio circundante, incidir en la cuarta dimensión (mediante el movimiento), conectar con un público improvisado, es decir, el testimonio casual de otros artistas, amigos, conocidos o contertulianos, y, en último lugar, hibridarse, de forma tímida, con otros registros de arte, que quedan pendientes de incorporarlos en la propia historia de la performance, tanto a nivel local como global.

\section{FUENTES REFERENCIALES:}

GONZÁLEZ MARTíNEZ, F. 2015. La incidència de l'agrupació artística d'Els Set (1948-1954) en les primeres petjades de l'art modern valencià del primer franquisme. Tesis doctoral. Valencia: Facultad de Bellas Artes, UPV.

KURTZ MUÑOZ, J. A. 1978. El pintor Salvador Tuset. Valencia: Intitució Alfons el Magnànim; Caja de Ahorros y Monte de Piedad de Valencia.

LLORENTE HERNÁNDEZ, A. 1995. Arte e ideología en el franquismo. Madrid: Visor.

MOLINA, M. "La performance española avant la lettre: del Ramonismo al Postismo (1915-1945)“ En Tejo, Carlos (ed.) Chámalle X. IV Xornadas de Arte de Acción. 2008. Vigo: Servicio de Publicaciones de la Universidad de Vigo.

MUÑOZ IBÁÑEZ, M. (et al:). 1986. Plástica valenciana contemporánea. Valencia: Promociones culturales del País Valencià

REAL ALARCón, M. 1985. Historia de los libros de Oro de las Tertulias de pintores y escultores valencianos. Valencia: Ayuntamiento de Valencia.

ROIG IZQUIERDO, A. 1982. Art viu del nostre temps. Valencia: Diputación de Valencia.

UREÑA, G. 1982. Las vanguardias artísticas en la postguerra española. 1940-1959. Madrid: Istmo.

Fuentes orales:

Entrevista a Juan Genovés enviada el 22 de octubre del 2016 y contestada, vía email, el 4 de diciembre de 2016.

Entrevista inédita con el pintor Vicente Gómez en su domicilio de Valencia, el día 16 de mayo de 2009.

Entrevista inédita con la pintora Ángeles Ballester, en su domicilio de Valencia, el día 22 de diciembre de 2009.

ANIAV Asociación Nacional de Investigación en Artes Visuales

This work is licensed under a Creative Commons Attribution-NonCommercial-NoDerivatives 4.0 International License (CC BY-NC-ND 4.0) 